\title{
A atuação do gestor escolar no enfrentamento da evasão no ensino médio da rede estadual paulista
}

\author{
The school principal's action towards addressing high school dropout in the \\ São Paulo state education network
}

\section{La actuación del director de escuelas en el enfrentamiento de la evasión en la enseñanza secundaria de la red estatal paulista}

\author{
Nonato Assis de Miranda ${ }^{2}$ \\ Cleidson Pereira Gonçalves ${ }^{3}$
}

\begin{abstract}
Resumo: Este artigo objetiva analisar as ações de gestores de escolas públicas da Secretaria de Estado da Educação de São Paulo (SEDUC-SP) para enfrentar os altos índices de evasão escolar apontados no Ensino Médio, visto que as práticas e as decisões desses profissionais podem gerar repercussões significativas na trajetória dos estudantes. Trata-se de uma pesquisa de abordagem qualitativa, cujos dados foram obtidos por meio de entrevistas com diretores de sete escolas públicas da SEDUC-SP. Os depoimentos dos diretores foram analisados e interpretados na perspectiva da Análise de Conteúdo de Laurence Bardin e à luz da literatura que discorre sobre o assunto. Os resultados mostram que, dentre outros elementos, o ingresso precoce do aluno no mercado de trabalho é o principal motivo da evasão escolar no Ensino Médio; contudo, a atuação dos gestores escolares tem sido fundamental para reduzir os altos índices de evasão escolar.
\end{abstract}

Palavras-chave: Gestão da Educação. Ensino Médio. Evasão escolar.

Abstract: This paper aims to analyze the school principals' actions of the São Paulo State Department of Education (SEDUC-SP) towards addressing the high dropout rates pointed out in High School, since the practices and decisions of these professionals can generate significant repercussions on the students' trajectory. This is a qualitative approach research, whose data were obtained through interviews with principals from seven public schools of SEDUC-SP. The school principals' statements were analyzed and interpreted from the perspective of Laurence Bardin's Content Analysis, and in the light of the literature on the subject. The results show that, among other elements, early student entry into the labor market is the main reason for dropouts in High School; however, the performance of school principals has been instrumental in reducing high dropout rates.

Keywords: Education Management. High School. School dropout.

Resumen: Este artículo tiene como objetivo analizar las acciones de los directores de escuelas públicas del Departamento de Educación del Estado de São Paulo (SEDUC-SP) para enfrentar los altos índices de evasión escolar encontrados en la Enseñanza Secundaria, ya que las prácticas y las decisiones de estos profesionales pueden generar repercusiones significativas en la trayectoria de los estudiantes. Se trata de una investigación de enfoque cualitativo, cuyos datos se obtuvieron por medio de entrevistas con directores de siete escuelas públicas del SEDUC-SP. Las declaraciones de los directores fueron analizadas e interpretadas desde la perspectiva del Análisis de Contenido de Laurence Bardin y a la luz de la literatura que trata sobre el tema. Los resultados muestran que, entre otros elementos, la entrada temprana del alumno en la actuación de los directores escolares ha sido fundamental para reducir los altos índices de evasión escolar.

Palabras clave: Gestión de la Educación. Enseñanza Secundaria. Evasión escolar.

\footnotetext{
${ }^{1}$ Submetido em: 14 set. 2019 - Aceito em: 24 ago. 2020 - Publicado em: 10 jan. 2021

${ }^{2}$ Universidade Municipal de São Caetano do Sul (USCS) - E-mail: mirandanonato@uol.com.br

${ }^{3}$ Centro Universitário Senac - E-mail: cleidson.pgoncalves@sp.senac.br
} 


\section{Introdução}

Este artigo insere-se em uma pesquisa realizada no Programa de Pós-Graduação em Educação da Universidade Municipal de São Caetano do Sul, que analisou as ações de diretores de escola no enfrentamento da evasão escolar no Ensino Médio (EM). A motivação para a realização da pesquisa deu-se por constatar que, a despeito de o Estado ter implantado políticas públicas de educação que garantiram, em sua quase totalidade, o acesso ao Ensino Fundamental (BRASIL, 1996), bem como estendido essa prerrogativa aos estudantes do EM, ainda assim, até o momento, as escolas não conseguem assegurar a permanência da maioria desses jovens na escola, fazendo com que não concluam a Educação Básica. Desse modo, boa parte desses estudantes acaba evadindo ou até mesmo abandonando a escola logo na primeira série do EM, gerando preocupações tanto para as famílias quanto para os governos e, principalmente, para os gestores escolares, que têm sido, cada vez mais, cobrados pela proposição de ações que minimizem esse problema.

Como esta pesquisa tem como foco a evasão escolar no EM e existe correlação entre matrícula, rendimento, evasão e abandono escolar, faz-se necessário tecer alguns comentários sobre esses termos. O número de matrículas serve de referência para o cálculo do fluxo escolar que indica a progressão de alunos de uma coorte, em determinado nível de ensino, em relação à sua condição de promovido, repetente ou evadido. Assim, as taxas de rendimento escolar de cada escola são geradas a partir da soma da quantidade de alunos aprovados, reprovados e que abandonaram a escola ao final de cada ano letivo (SILVA, 2017).

Com relação aos termos "evasão" e "abandono", apesar de haver compreensões diferentes sobre o assunto, para nós, o abandono ocorre quando o aluno deixa de frequentar as aulas durante o ano letivo, e a evasão quando ele abandona a escola ou reprova em determinado ano letivo e não realiza sua matrícula, no ano seguinte, para dar continuidade aos estudos.

São vários os fatores que colaboram para que o estudante evada ou até mesmo abandone a escola no EM, cujas causas podem estar atreladas às questões escolares, às circunstâncias familiares e, principalmente, na dimensão econômico-social. Com relação àqueles relacionados à escola em si, podemos citar, dentre outros elementos, o convívio precário com colegas de sala, docentes e demais integrantes da comunidade escolar, salas extremamente lotadas, excesso de conteúdo, professor mal preparado, pais que deixam de lado o aprendizado de seus filhos, escassez de tempo para o aluno realizar as atividades escolares (SOUSA et al., 2011). No entanto, um problema que repercute de forma incisiva na evasão escolar são as sucessivas reprovações (MENDES, 2013).

Há, também, outros agravantes que transcendem a dimensão escolar, mas que têm um peso muito grande sobre a evasão nesse nível de ensino. Dentre outros, citamos as questões inerentes à família, como, por exemplo, o nível educacional dos pais, a renda e a estrutura social da família (LÜSCHER; DORE, 2011); a necessidade de inserção no mercado de trabalho (CAMARGO; RIOS, 2018); o envolvimento com atividades ilícitas (LOPES; SANTOS, 2015). Em síntese, as causas da evasão escolar são variadas, podendo ser desde condições socioeconômicas, culturais e geográficas, bem como questões referentes aos 
encaminhamentos didático-pedagógicos e a baixa qualidade do ensino público.

Dentre os motivos mais frequentes, alegados pelos pais ou responsáveis para a evasão dos alunos, a partir dos anos finais do Ensino Fundamental e pelos próprios alunos no EM, destacamos: ajudar em casa ou no trabalho, necessidade de trabalhar, falta de interesse e proibição dos pais de ir à escola (CAMARGO; RIOS, 2018; LOPES; SANTOS, 2015; MENDES, 2013; LÜSCHER; DORE, 2011).

Esse quadro constitui-se em um paradoxo quando se constata que, em conformidade com o contido no Artigo $4^{\circ}$ da Lei de Diretrizes e Bases da Educação (LDB), é dever de o Estado garantir a Educação Básica, obrigatória e gratuita (BRASIL, 1996) a todas as crianças e a todos os jovens. Para tanto, esse mesmo dispositivo legal define essa incumbência à União, aos Estados, ao Distrito Federal e aos Municípios, os quais devem estabelecer competências e diretrizes que norteiem os currículos e seus conteúdos mínimos de modo a assegurar a formação básica comum. Busca também elevar o nível de escolaridade da população, promovendo a melhoria da qualidade do ensino em todos os níveis e a preparação dos estudantes para o mundo do trabalho de forma a atender as demandas regionais e locais da sociedade (BRASIL, 1996).

Não obstante, o que se constata é que no EM o Estado não tem logrado o êxito esperado quanto ao cumprimento dessa demanda. Em razão disso, temos observado a implantação de um conjunto de ações públicas com o intuito de equacionar o problema que, na maioria das vezes, é planejado por técnicos que estão distantes da realidade escolar. Assim sendo, boa parte desses técnicos desconhecem a complexidade do fenômeno, mas, mesmo assim, cobram dos gestores o cumprimento de metas que, por vezes, estão bem distantes da realidade das escolas.

Nesse sentido, algumas soluções que minimizam a evasão escolar dependem intrinsecamente de ações do poder público, ao passo que outras podem ser propostas e implementadas pelos gestores escolares e suas equipes. Todavia, não há como pensar em equacionar o problema sem compreender que, por trás da evasão escolar, no EM, há outras questões muito graves que não estão no âmbito da governabilidade dos gestores escolares.

Em face ao exposto, essa pesquisa buscou compreender as ações empreendidas por gestores de escolas de EM, da Secretaria de Estado da Educação de São Paulo (SEDUC-SP), diante de sua autonomia relativa no enfrentamento da evasão escolar.

\section{Possíveis causas da evasão escolar}

Antes de citar as causas da evasão escolar, é importante destacarmos que esse fenômeno, historicamente, “[...] faz parte dos debates e reflexões no âmbito da educação pública brasileira", tendo adquirido grande "[...] relevância no cenário das políticas públicas e da educação em particular [...]" (MILLEN NETO et al., 2010, p. 3), com maior ênfase a partir da década de 1990, com o advento das políticas educacionais orientadas pelo modelo neoliberal. A partir de então, o que se observa é que, em certa medida: 
[...] a educação é transferida do âmbito dos direitos para o âmbito privilegiado do mercado, transformando-a de um direito social para um serviço, uma mercadoria que deve ser adquirida no livre mercado, uma vez que a educação é redefinida segundo a lógica do mercado pelas reformas neoliberais (COSTA JR., 2010, p. 44).

Com isso, passou-se a privilegiar, cada vez mais, a garantia de acesso e permanência do estudante na escola sem a devida preocupação com a qualidade do ensino. Uma das maiores preocupações com a garantia desse princípio é a da manutenção do aluno na escola, evitando-se, portanto, a evasão ou o abandono escolar. Contudo,

[...] a democratização da educação não se limita ao acesso à instituição educativa. O acesso é, certamente, a porta inicial para a democratização, mas torna-se necessário, também, garantir que todos os que ingressam na escola tenham condições de nela permanecer, com sucesso. Assim, a democratização da educação faz-se com acesso e permanência de todos no processo educativo, dentro do qual o sucesso escolar é reflexo da qualidade. Mas somente essas três características ainda não completam o sentido amplo da democratização da educação (BRASIL, 2010, p. 45).

Assim, sem muita preocupação com os aspectos qualitativos, buscam-se, cada vez mais, os culpados pela evasão escolar, que se tornou um elemento central para o insucesso das políticas educacionais, então, promulgadas. Nesse contexto, observa-se que, em geral, as discussões a respeito da evasão escolar giravam em torno da intersecção entre os papéis da escola e da família no que tange às responsabilidades da vida escolar do aluno (QUEIROZ, 2007).

Apesar da complexidade que está por trás da evasão escolar, esse fenômeno manifesta-se de diferentes formas, tais como: saída do aluno da escola e/ou do sistema de ensino, abandono e futuro retorno à escola, retenção e repetência discente. Entretanto, o que o sistema educacional entende como evasão não é o mesmo no ponto de vista do aluno ou até mesmo para a escola que ele frequentou (LÜSCHER; DORE, 2011). Assim sendo, essas diferentes perspectivas sobre o tema dificultam a proposição de ações por parte dos gestores escolares para mitigar a evasão escolar.

Em geral, para o sistema de ensino público readmitir um aluno, decorridos dez anos de sua desistência, pode ser considerado um problema, mesmo que o aluno ou a escola tenha outra visão sobre a situação. Independentemente de qualquer coisa, devem ficar bastante nítidas as possíveis relações entre as perspectivas do sistema escolar, da escola e do aluno, visando saber qual é a principal visão de cada um deles (LÜSCHER; DORE, 2011).

Há um conjunto de fatores que influenciam a evasão escolar; dentre outros, estão as razões psicológicas inerentes aos fatores cognitivos e psicoemocionais e as razões socioculturais referentes ao contexto social dos alunos, bem como as características familiares. No entanto, há também os fatores escolares que são os mais variados (MENDES, 2013) e as questões socioeconômicas. Lüscher e Dore (2011) asseveram que o convívio do aluno com os demais colegas, com os docentes e, inclusive, com os demais integrantes da comunidade escolar, é fator decisivo para que o jovem tome a decisão de evadir ou continuar na instituição de ensino, por exemplo.

As características do ambiente escolar, tais como, comportamento dos colegas, recursos escolares, estruturas físicas, relacionamento dos professores e até mesmo os 
processos pedagógicos podem favorecer a evasão escolar. A circunstância familiar (grau educacional dos pais, renda familiar e estrutura social da família) é também um fator importante para o sucesso ou fracasso escolar do aluno (LÜSCHER; DORE, 2011). Outro fator significativo, relacionado à família, que colabora para a evasão escolar, é a qualidade do convívio que o aluno tem com seus pais.

De acordo com Camargo e Rios (2018), a maioria dos jovens que evadiram das escolas se encontra nas áreas urbanas, precisando ser inserida no mercado de trabalho e, por isso, toma essa decisão. As motivações para essa evasão são diversas, mas Sousa et al. (2011) alegam que pesquisas e estudos realizados para analisarem a evasão escolar abordam duas teorias: situações externas e internas à instituição escolar. As situações externas estão relacionadas ao trabalho, às desigualdades sociais, à relação com a família e às drogas. As situações internas estão associadas à própria escola, incluindo o professor.

Embora haja a obrigatoriedade do EM para os jovens, Lopes e Santos (2015) salientam que a primordialidade do trabalho para ajudar na renda familiar, somada a uma carga horária bastante cansativa afetam no desempenho dos alunos com relação aos estudos. Adicionalmente, os alunos que têm um nível socioeconômico mais baixo possuem um menor rendimento, ficando, assim, mais dispostos à evasão. Além disso, Mendes (2013) alega que a falta de motivação do aluno interfere no seu processo de aprendizagem. Com a ausência de certa disposição, o estudante deixa de investir na realização de tarefas com o mínimo de qualidade, tendo como resultado uma formação deficitária para exercer a cidadania e realizarse como pessoa.

Outro motivo para a evasão escolar, segundo Lopes e Santos (2015), é o envolvimento com atividades ilícitas. O ingresso na criminalidade e na violência também é destacado pelos autores, mas não podemos ignorar que questões como salas de aula muito cheias, excesso de conteúdo (e, também, bastante desinteressante), professor mal preparado, pais que deixam de lado o aprendizado de seus filhos, escassez de tempo para a realização de atividades escolares (SOUSA et al., 2011), dentre outros, são fatores decisivos para a evasão escolar no EM.

É oportuno mencionarmos que, além da baixa qualidade do ensino, a reprovação, a falta de interesse por parte do aluno, a burocracia escolar, as brincadeiras de mau gosto por partes de colegas também incentivam o aluno a abandonar os estudos antes da conclusão do EM. Sobre esse assunto, Mendes (2013) denuncia que 75\% dos estudantes acham que o principal problema desse nível de ensino são os alunos desinteressados. Esse quadro é preocupante, pois, segundo Sousa et al. (2011), normalmente, os alunos que estão cogitando o abandono escolar acabam fazendo isso sem qualquer tipo de comunicação aos pais (ou seu responsável), principalmente quando maiores de idade. Esses autores expressam a ideia de que a instituição de ensino tem uma grande responsabilidade pelo sucesso ou fracasso dos alunos, destacando aqueles que pertencem às classes sociais mais baixas da população. Ocorre que, muitas vezes, "[...] a escola desconsidera o capital cultural de seus estudantes da classe pobre, sendo o professor responsabilizado pela evasão e pelo fracasso escolar do aluno" (SOUSA et al., 2011, p. 28).

Ademais, estudos apontam que as sucessivas reprovações são um fenômeno que agrava a interrupção dos estudos escolares. Em razão disso, “[...] a evasão escolar deve ser 
vista como um processo e não apenas como um momento pontual na vida do estudante" (MENDES, 2013, p. 263). Para esse autor, a evasão escolar é a etapa final de um acumulativo e tenso desempenho da escola.

Trombini, Olegrário e Laroque (2017) explicam que o problema que acarreta a evasão escolar não é culpa do aluno, da família ou do professor, especificamente. Sugerem, portanto, que se deve levar em consideração o que de fato está sendo feito na instituição de ensino. Os autores apontam também que, embora o assunto esteja sendo discutido há algum tempo por muitas escolas, o tema deve ser repensado, pois a cada ano o número de alunos que deixa a escola no EM só aumenta, sendo as taxas de reprovação cada vez maiores, caracterizando, assim, o fracasso escolar.

Outro problema situado por Mendes (2013) é que, às vezes, a evasão escolar é vista por cada membro que compõe a comunidade escolar de forma distinta. Nesse sentido, o autor alega que, na visão do gestor escolar, a evasão se dá em virtude da ausência de incentivos estudantis, pois tendem a associar a aprendizagem às necessidades profissionais dos estudantes. Por sua vez, na perspectiva da coordenação pedagógica, a evasão escolar ocorre, principalmente, pelo rendimento ruim do aluno, haja vista que, quando este se depara com uma nota baixa, fica desmotivado, a ponto de querer abandonar os estudos. Isso porque o aluno se acha incapaz de recuperar o conteúdo trabalhado, bem como as notas para ser aprovado. Já para o docente, a evasão escolar está relacionada às condições econômicas e sociais da família e do estudante (MENDES, 2013).

Todavia, existem outras concepções que ajudam explicar a evasão escolar. Segundo Rumberger (2006 apud MENDES, 2013), por exemplo, os recursos que a instituição escolar oferece ou deixa de oferecer podem tanto influenciar na efetivação do engajamento e do desempenho econômico, quanto contribuir para o processo de desengajamento e evasão do estudante. De acordo com Diniz e Quaresma (2016), o formato tradicional do EM somado à estrutura administrativa, institucional e física da escola corrobora para a decisão do jovem em abandonar os estudos em pleno período escolar. Para essas autoras, existe a necessidade de obter-se uma educação de qualidade que deixe o aluno apto para o exercício da cidadania.

Aulas diversificadas e atrativas, qualificação e valorização dos profissionais envolvidos com o ensino, investimentos financeiros cada vez maiores e ampliação dos momentos de socialização podem fazer com que o estudante perceba que o conhecimento obtido em sala de aula tenha utilidade no seu dia a dia fora da escola (DINIZ; QUARESMA, 2016). Ademais, “[...] mesmo com todas as medidas governamentais que chegam à escola, o grupo de gestores deve procurar estabelecer estratégias e práticas educacionais e se preocupar com a aprendizagem de seus alunos, principalmente para reduzir os índices de evasão e reprovação" (TROMBINI; OLEGRÁRIO; LAROQUE, 2017, p. 146). Assim sendo, é imprescindível o uso de diferentes linguagens com os alunos devido à complexidade para a troca de ideias e experiências com vistas a propor soluções efetivas e ampliar a importância de cada estudante dentro da vida escolar. 


\section{Procedimentos metodológicos}

Dados os objetivos dessa pesquisa, optamos pela abordagem qualitativa porque esse método vem proporcionando, há várias décadas, grandes contribuições para o avanço do conhecimento em educação. Os sujeitos participantes da pesquisa foram sete gestores de escolas públicas da SEDUC-SP, cuja escolha dessas escolas deu-se a partir de uma análise prévia do fluxo (relação entre promoção, evasão e abandono) de 2018, do total de escolas da Diretoria de Ensino da capital paulista. Foram selecionadas três escolas que apresentaram, nesse ano, baixos índices de evasão e abandono e quatro com altos índices de evasão e abandono.

Os dados foram obtidos por meio de um roteiro semiestruturado que norteou a entrevista, o que não impediu que outras questões inerentes ao assunto fossem abordadas durante a entrevista. Embora a pesquisa original tenha proposto cinco questões, neste artigo, estão apresentados os resultados de três delas. As respostas, obtidas entre fevereiro e março de 2019, foram organizadas, classificadas e categorizadas, considerando-se a semelhança entre si na perspectiva da Análise de Conteúdo (BARDIN, 2004). Os nomes atribuídos às categorias, bem como suas definições foram escolhidos a partir da ideia central das respostas apresentadas e do embasamento teórico adotado no trabalho (CAMARGO; RIOS, 2018; LOPES; SANTOS, 2015; MENDES, 2013; LÜSCHER; DORE, 2011).

Para garantir o sigilo acerca da identidade dos participantes, foi utilizada a letra "G" para Gestor(a) e um número para diferenciá-los. Todos os gestores estavam à vontade durante as entrevistas, permitindo que expressassem sua percepção sobre o tema da pesquisa, pois foi-lhes garantido o anonimato.

\section{Criando categorias}

Partindo do pressuposto de que a categorização diz respeito a colocar cada elemento em um grupo comum a ele (BARDIN, 2004), nessa pesquisa as categorias estão atreladas ao agrupamento das indagações durante a entrevista, as quais trazem respostas bastante similares. Contudo, neste artigo, em razão de sua dimensão, apresentamos, a seguir, apenas três categorias de um conjunto de cinco, quais sejam: motivos da evasão escolar; evasão escolar no EM: um desafio para o gestor; e as políticas públicas de educação e a evasão escolar.

\section{Categoria 1: Motivos da evasão escolar}

Nesta categoria, foram agrupados os questionamentos e as percepções dos gestores escolares acerca da evasão escolar no EM e os fatores que possivelmente provocam a evasão escolar. Para tanto, foi realizada a seguinte indagação: "Segundo Censo Escolar de 2017, algumas escolas têm dificuldade em lidar com a questão da permanência de alunos, na escola, 
tendo em vista que muitos deles acabam evadindo e, por conta disso, não concluem o EM. Em sua opinião, por que isso tem acontecido com certa frequência e quais seriam os principais fatores que fomentam esse fenômeno?".

As respostas obtidas permitiram explorar um dos principais motivos que fomentam a evasão escolar, qual seja: o ingresso no mercado de trabalho, seja por vontade própria do aluno, seja por necessidade familiar, conforme pode ser constatado nesse depoimento, por exemplo:

\footnotetext{
O aluno do EM tem outros objetivos além da escolarização. Ele prefere ir para o mercado de trabalho, buscar cursos e aí ele se envolve mais com o curso e esquece a educação básica mesmo esse curso não sendo o suficiente sem a educação básica. Mas, a família não tem essa consciência. Aliás, nem a família nem tampouco o aluno tem; então, esse é o grande problema (G1).
}

Muitas vezes, o aluno não vai para o mercado de trabalho por necessidade ou desejo da família, mas por vislumbrar oportunidades de acordo com seu objetivo de vida momentâneo. Como, em geral, os pais não têm o discernimento necessário para manter o jovem na escola, eles o direcionam ao mercado de trabalho precocemente. Entretanto, ainda sobre a inserção do aluno que está cursando o EM, no mercado de trabalho, um segundo participante da pesquisa fez o seguinte comentário: "O aluno abandona [a escola] porque tem que sustentar uma família. Na nossa comunidade, a gente encontra muito isso. Ele é o único responsável, às vezes, financeiramente pela família, então, ele precisa começar a trabalhar e, por conta disso, abandona os estudos" (G2).

Realizando uma análise mais pontual desse depoimento, notamos que esse gestor compreende o problema e, em certa medida, o motivo pelo qual o aluno evade da escola para poder trabalhar e, assim, ajudar financeiramente sua família. Grosso modo, esse tipo de problema ocorre com mais frequência com os estudantes que se encontram nas áreas urbanas das grandes cidades (CAMARGO; RIOS, 2018).

Um segundo gestor endossou que esse problema é comum no EM, tendo em vista que ele teceu o seguinte comentário: "[...] é por causa da opção pelo trabalho em detrimento da escola que está a principal causa da evasão. Eles começam estudando e trabalhando, mas eles não aguentam; e aí, vão desistindo no caminho, no meio do caminho do EM" (G4). Partindose do pressuposto de que, em geral, um profissional trabalha cerca de oito horas diárias e que, além disso, levam até quatro horas no percurso entre a casa, o trabalho e a escola, torna-se bastante difícil para o aluno conciliar trabalho e escola, pois, em geral, chega à escola exausto, impedindo-o de concentrar-se nas aulas.

Portanto, a despeito de a legislação exigir que os jovens concluam o EM, suas condições socioeconômicas fazem com que eles acabem priorizando o trabalho em detrimento dos estudos, levando-os à evasão escolar. Isso ocorre, dentre outras coisas, pela dificuldade de conciliar uma carga horária elevada de trabalho com a de estudos (LOPES; SANTOS, 2015).

Cabe destacarmos, ainda, que a situação econômica vivida pelos brasileiros, nos últimos anos, bem como as altas taxas de desemprego, além de tirar os estudantes das escolas, os levam para o emprego informal, pois: 
Um dos grandes motivos [da evasão escolar], até mesmo no final do curso, é a questão do trabalho. Trabalho informal que eles fazem e não dão conta... depois de vir para escola. O menino, maneira de dizer, porque tem menina também que trabalha [...]. Eu, lá na praça Oswaldo Cruz, outro dia, fui jantar, era umas 9 horas da noite, eu estava voltando e dei de cara com um menino vendendo bala lá nessa praça, era nosso aluno! Um menino de 15 anos (G6).

Ultimamente, os jovens e as ruas têm tido uma relação bastante estreita. Os alunos acham os espaços urbanos mais interessantes do que os conteúdos escolares. Isso acontece porque "[...] a escola não é atrativa para o aluno, por isso, ele acaba se evadindo da escola; não tem nenhum interesse pela escola; não tem sentimento de pertencimento com a escola e isso é fundamental" (G5). Esse mesmo gestor afirmou que a pouca atratividade das aulas também favorece a evasão do estudante do EM. Contudo, há outros fatores que fomentam a evasão, como a localização geográfica da escola, por exemplo:

\begin{abstract}
Nós estamos numa escola que ela é considerada uma escola de passagem, pela localização. Então, a gente tem um percentual muito grande de alunos que não moram na região e isso é um dificultador. Aqui, particularmente, a gente tem muito problema em relação a isso, os pais vêm trabalhar aqui na região e querem trazer os filhos para ficarem perto, estudar aqui, mas quando o pai sai do emprego e volta para o bairro de origem, o pai leva a criança [jovem] embora da escola, isso é bastante comum aqui [...] (G6).
\end{abstract}

Esse ponto de vista foi corroborado por um segundo gestor que teceu o seguinte comentário sobre o assunto: "Muitos alunos mudam de bairro e acabam saindo da escola, mudam da cidade, outros desistem mesmo porque moram com a vó ou com o vô, "não tem pai e mãe', então, decidem parar o estudo e somem da escola" (G7).

Em síntese, a evasão escolar faz com que a distorção idade-série seja cada vez maior e, com isso, favorece o aumento do índice de analfabetismo funcional. Isso é grave, pois dificulta ainda mais a vida desses jovens que acabam não conseguindo um emprego bem remunerado. Portanto, os gestores precisam atentar para o fato de que, apesar de essas taxas de distorção série-idade não serem as mais altas entre os pais latino-americanos (KRAWCZYK, 2011), a pouca atratividade das escolas tende a favorecer o abandono escolar e, portanto, o aumento desses indicadores.

\title{
Categoria 2: Evasão escolar no Ensino Médio: um desafio para o gestor
}

As escolas que participam do Programa de Ensino Integral (PEI) possuem baixos índices de evasão escolar no EM, inclusive, na maioria das escolas participantes desse programa, esse índice é zero. Contudo, há um índice alto de transferências para a escola regular para que os estudantes conciliem estudo e trabalho.

Com o intuito de conhecer as estratégias de trabalhos adotadas por esses gestores para minimizar o número de transferência e, até mesmo, evitar a evasão, verificamos que os gestores têm uma preocupação em fazer com que o aluno se sinta pertencente à escola. Para eles, essa premissa é uma ferramenta poderosa contra a evasão escolar, conforme apontado no depoimento: 
A palavra aqui é a "pedagogia da presença", a partir da qual o aluno se sente pertencente à escola; ele percebe a importância de estudar e sabe que a gente o prepara para o mundo lá fora. [...]. Então, aqui a gente oferece o que acreditamos ser um diferencial que ele não encontra em qualquer outra escola, como, por exemplo, a preocupação com a aprendizagem (G1).

Embora esse relato nos permita inferir que, para essa gestora, a escola que faz parte do PEI tenha um diferencial grande e que se preocupa mais com a aprendizagem dos alunos quando comparada às demais escolas, não há dúvidas de que a atenção deles para com os alunos é grande. A ideia é deixar claro para os alunos que a escola não é somente sala de aula, mas um todo, é local de desenvolvimento humano em uma perspectiva interdimensional. Isso é importante porque a ausência de motivação do aluno poderá interferir no processo de aprendizagem, de modo a fazer com que eles deixem de realizar suas tarefas com qualidade, prejudicando sua formação para o exercício pleno da cidadania (MENDES, 2013).

É oportuno mencionarmos que muitas dessas escolas têm um diferencial de infraestrutura, bem como contam com: "[...] professor-tutor que acompanha de perto o aprendizado do aluno, sua frequência, seu desempenho e, com base nesse processo, orienta e mantém os pais informados sobre a vida escolar dos alunos" (G3).

Vale destacarmos que muitos gestores escolares afirmaram que, quando os pais são presentes na vida escolar dos filhos, certamente as notas obtidas nas avaliações são maiores e a probabilidade de o aluno evadir é muito menor. Para eles, quando há incentivos para os estudos que associem as necessidades pessoais dos alunos, as possibilidades de evasão são pequenas.

Para Lüscher e Dore (2011), a forma como os alunos são tratados pelos colegas, pelos professores e demais agentes escolares é fundamental para o sucesso e a permanência deles na escola. Portanto, os gestores precisam estar atentos às práticas e ao currículo escolar (TROMBINI; OLEGRÁRIO; LAROQUE, 2017).

A principal ação para que o aluno não se evada da escola é o acompanhamento diário dele em sala de aula. Assim, quando é detectada sua ausência, a gestão comunica-se imediatamente com as famílias, buscando saber o que aconteceu.

A gente faz um acompanhamento praticamente diário, o aluno que falta três vezes seguidas recebe uma ligação, se for menor de idade [a maioria é], o contato é feito com o responsável para saber o porquê das ausências. Os que ficam mais tempo afastados, a gente pede para retornar à escola com o responsável, para conversarmos, para ver qual é o problema, para sabermos se tem alguma adequação a ser feita para que ele conclua o ano letivo (G4).

Apesar de todo esse esforço da gestão para que o aluno não falte às aulas, nem sempre esse processo é bem-sucedido. Por vezes, esse contato não tem o retorno esperado e, a partir disso, a gestão acaba tendo que tomar atitudes mais pragmáticas, mas sempre de acordo com a legislação.

A gente tem o acompanhamento sistemático, a coordenação durante, as ATPC [Aula de Trabalho Pedagógico Coletivo], conversa com os professores que também estão atentos buscando saber se há alunos que não estão comparecendo às aulas. 
Quando isso acontece, a gente faz primeiro o contato telefônico; não deu jeito, a gente faz o contato formal; o aluno não voltou, a gente encaminha para o Conselho Tutelar, embora, não tenha muito resultado (G6).

Notamos, portanto, que o encaminhamento do problema ao Conselho Tutelar é apenas uma ação formal, pois o retorno obtido é praticamente nulo. Esse mesmo gestor acrescentou que o Conselho Tutelar é "[...] quem conseguiria fazer uma pressão com os pais, mas demora; às vezes, o pai é chamado no ano seguinte da notificação que a gente fez" (G6). Sobre o mesmo assunto, outro gestor afirmou que,

[...] quando a gente não consegue [contato] com o aluno, é com a família e, no caso de menores, o encaminhamento para o Conselho Tutelar. [Porém] não, não funciona. É mais por uma questão burocrática porque o retorno dele [aluno] é mais eficaz quando a gente realmente conversa com aluno e tenta explicar. Mas, assim, quando ele realmente já está evadido, não tem mais o contato com o aluno, essa questão do Conselho Tutelar, infelizmente, é perda de tempo, a gente não tem retorno; a informação vai e morre lá, fica lá (G2).

Esses depoimentos mostram que, diferentemente do preconizado na legislação vigente, o Conselho Tutelar não vem atuando em parceria com as escolas e as famílias para colaborar com a minimização da evasão e o abandono escolar no EM.

\section{Categoria 3: As políticas públicas de educação e a evasão escolar}

As políticas públicas de educação e os programas de governo são indispensáveis para acabar com a evasão escolar. Em razão disso, temos observado que alguns governos criam diversas medidas para atingir esse objetivo (TROMBINI; OLEGRÁRIO; LAROQUE, 2017). Como nem sempre esses programas são eficazes, buscamos conhecer as percepções dos gestores sobre o assunto, pois, em São Paulo, há iniciativas governamentais nesse sentido, como o "Quem falta faz falta" e o projeto "Busca Ativa". Contudo, os depoimentos mostram que os gestores estão mais familiarizados com o primeiro programa.

No programa "Quem falta faz falta", o gestor escolar e sua equipe constatam as ausências dos alunos, identificam os motivos e apontam ações estratégicas para sanar o problema. Em conjunto aos órgãos colegiados, tais como Grêmio Estudantil e Associação de Pais e Mestres, colocam em prática, nas aulas regulares, ações diversificadas desenvolvidas com o intuito de estimular o entusiasmo do aluno (SÃO PAULO, 2017).

Contudo, para os gestores entrevistados, o programa "Quem falta faz falta" não produz os resultados esperados, porque o problema da evasão está relacionado à família do aluno. Em geral, na percepção dos gestores, não há comprometimento da família com a vida escolar do filho, conforme evidenciado no depoimento a seguir:

A questão não é "in loco" escola. Então, a questão é responsabilização dos pais, é questão de família mesmo. A partir do momento que o aluno está faltando, porque perde a hora. [...] porque aqui a gente tem casos de aluno que não vem para escola porque o pai ou a mãe perde a hora com frequência. Também é uma realidade. Aí a gente força, fica ligando e o aluno volta para o ambiente escolar. Só que ele não tem nenhum acompanhamento em casa e não considera a educação como base, como 
projeto de vida dele. Aí, começa a complicar demais. Não existe uma valorização da educação fora do ambiente escolar (G3).

Do mesmo modo, um segundo gestor coloca em dúvida a eficiência desse programa. Para ele, apesar dos objetivos audaciosos do governo, o projeto "Quem falta faz falta não tem efetividade na redução da evasão escolar (G2). Depreendemos da fala do gestor que esse programa é praticado com aquele aluno que tem excesso de faltas sem justificativa, simplesmente por falta de vontade de frequentar a escola. Isso faz com que esse jovem seja promovido independentemente da recuperação do conhecimento perdido.

Por conta disso, alguns gestores optam por criar métodos próprios para minimizar o problema da evasão, porque não acreditam na proposta governamental.

Eu não fico dependendo de fora; é aqui dentro que está o problema, então, é aqui dentro que a gente vai resolver. Até que eles colocam esse projeto aí Quem Falta Faz Falta [sinal de negativo]. Eles [Diretoria de Ensino] estão chamando muito o grêmio para participação porque o grêmio acaba também fazendo com que aluno acabe mobilizando a escola para determinadas situações. Conhecer, fazer com que a gente viva aqui, a gente nem pensa no que acontece fora (G5).

Ainda assim, a SEDUC-SP vem mostrando que o projeto traz bons resultados. De acordo com a Secretaria de Estado da Educação de São Paulo, esse programa fez com que $60 \%$ dos alunos com excesso de faltas retornassem aos estudos para concluir o ano letivo. Isso faz com que o estado de São Paulo tenha um dos menores índices de faltas nas escolas brasileiras (SÃO PAULO, 2017). Contudo, pela ausência de resultados efetivos, respondendo à indagação feita durante a entrevista, alguns gestores não concordam com esse ponto de vista e sugerem outros encaminhamentos, como aponta o gestor a seguir:

Eu acredito muito que se as escolas tivessem uma Assistente Social ajudaria bastante. Pois, tem muitos [alunos] que não conseguem conciliar o trabalho e a escola. Também tem os motivos familiares, motivos de moradia, moram muito longe, vem trabalhar no centro, então, estuda numa escola no centro, aí fica cansado para ir embora. Então, eu acho que uma orientação de uma Assistente Social ajudaria bastante os alunos a organizar a vida deles. Nós tentamos fazer isso, mas nós não somos profissionais disso (G4).

O que a gestão sinaliza aqui é que ela sozinha não consegue resolver todos os problemas da escola, pois suas demandas são muitas, e esses projetos são criados por técnicos de gabinete que desconhecem a realidade escolar. Como sugestão, o gestor propõe a vinda de um especialista em situações de vulnerabilidade social. Todavia, há também aqueles que acreditam que os professores conseguiram resolver o problema, mas, para tal, faz-se necessário haver coerência entre o número de docentes e as demandas da escola.

[...] a gente acredita que, de repente, se tivesse mais professores, inclusive, até um professor de apoio na sala de aula acho que seria uma política pública interessante de se implementar. Porque o professor, muitas vezes, numa sala com 40 alunos, que é a quantidade de alunos prevista no EM, não consegue dar uma atenção individualizada para esse aluno que apresenta uma defasagem o que o desmotiva e até mesmo faz com que ele evada da escola. Então, eu acho que seria interessante apontar que a presença de uma pessoa qualificada... e dentro do mesmo turno, porque essa questão de fazer um trabalho de recuperação no contraturno... a gente encontra muita dificuldade para que o aluno volte no contraturno $(\mathrm{G} 2)$. 
A preocupação desse gestor está centrada nas condições de ensino, o que acaba dificultando o trabalho docente. Ele considera que a dificuldade do professor em dar atenção a todos os alunos de forma mais individualizada é um fator que pode colaborar para a evasão escolar. Uma alternativa seria a proposição de um professor de apoio que já fez parte dessa rede de ensino, mas foi suspensa e voltou em 2019, no segundo semestre.

O reforço escolar tem sido uma das medidas que as escolas praticam como estratégia para minimizar o fracasso estudantil, porém essas intervenções são limitadas por causa das condições de infraestrutura e de financiamento específico, as quais interferem na frequência e na permanência do aluno (REAL et al., 2019).

Em síntese, com vistas à evasão escolar, alguns gestores tendem a aplicar ações alinhadas com os programas governamentais, mas o sucesso de suas iniciativas tem encontrado algumas barreiras diante de um cenário bastante caótico e cheio de restrições.

\section{Considerações finais}

Esta pesquisa mostra que os desafios enfrentados pelos gestores escolares para minimizar a evasão no EM são cada vez maiores, pois a necessidade de se ingressar no mercado de trabalho faz com que o aluno coloque os estudos em segundo plano. Isso acontece, dentre outras coisas, porque as condições socioeconômicas desses jovens os obrigam a escolher entre a conclusão do EM e a busca por um emprego, corroborando os resultados de outras pesquisas (CAMARGO; RIOS, 2018).

Como a garantia de permanência do estudante na escola faz parte das metas da gestão das escolas da SEDUC-SP, as equipes escolares empreendem ações com o intuito de conter a evasão no EM. Grosso modo, essas ações têm focos diferentes, como a motivação do aluno, a qualificação do professor, a defasagem e as especificidades de cada aluno, a recuperação de conteúdo e o fortalecimento da relação professor-aluno de acordo com a realidade e as necessidades de cada escola. Entretanto, dentre as sete escolas investigadas, cinco delas apresentaram ações específicas sobre fluxo escolar, incluindo nesse conjunto de ações a evasão.

As escolas, cujas ações não tiveram foco na redução da evasão escolar, são as que apresentaram os maiores problemas com evasão e abandono de alunos no EM, nos últimos anos. Além disso, nessas escolas, os gestores mostraram-se menos preocupados em implantar ações mais direcionadas ao fluxo, seja por não acreditarem nos projetos do governo, seja por transferirem a responsabilidade da evasão para outros profissionais da escola como, por exemplo, o vice-diretor ou professor coordenador.

Em face ao exposto, apesar da obrigatoriedade do EM, nos termos da legislação vigente, as condições socioeconômicas de boa parte dos jovens fazem com que eles acabem priorizando o trabalho em detrimento da continuidade de estudos no EM, levando-os à evasão e, até mesmo, ao abandono escolar. Entendemos que esse problema deve ser enfrentado tanto por meio de políticas públicas quanto por ações mais pontuais da gestão escolar, pois a conclusão do EM, além de ser um fator primordial para a garantia da empregabilidade, 
possibilita o prosseguimento de estudos em nível superior, e o que é mais importante, “[...] o aprimoramento do educando como pessoa humana, incluindo a formação ética e o desenvolvimento da autonomia intelectual e do pensamento crítico" (BRASIL, 1996, p. 18).

\section{Referências}

BARDIN, Laurence. Análise de conteúdo. Lisboa: Edições 70, 2004.

BRASIL. Lei no 9.394, de 20 de dezembro de 1996. Estabelece as diretrizes e bases da educação nacional. Diário Oficial da União, Brasília, DF, 23 dez. 1996.

BRASIL. Ministério da Educação. Construindo o sistema nacional articulado de educação: O Plano Nacional de Educação, diretrizes e estratégias de ação. DocumentoReferência CONAE 2010. Brasília, DF: MEC, 2010. Disponível em:

http://portal.mec.gov.br/arquivos/pdf/conae/documento_referencia.pdf. Acesso em: 14 out. 2018.

CAMARGO, Douglas Branco de; RIOS, Mônica Piccione Gomes. Evasão escolar na $1^{\text {a }}$ série do ensino médio: o caso de Joaçaba, Santa Catarina. Eccos - Revista Científica, São Paulo, n. 46, p. 33-51, maio/ago. 2018. https://doi.org/10.5585/eccos.n46.4287.

COSTA JR., Wercy Rodrigues. Política educacional no contexto do neoliberalismo. Revista da Faculdade de Educação, São Paulo, ano VIII, n. 13, p. 31-49, jan./jun. 2010.

DINIZ, Carine Saraiva; QUARESMA, Adilene Gonçalves. Evasão de jovens do ensino médio: causas intraescolares segundo os evadidos de uma escola pública. Camine:

Caminhos da Educação, Franca, v. 8, n. 2, p. 113-134, 2016.

KRAWCZYK, Nora Rut. Reflexão sobre alguns desafios do ensino médio no Brasil hoje. Cadernos de Pesquisa, São Paulo, v. 41, n. 144, p. 752-769, set./dez. 2011. http://dx.doi.org/10.1590/S0100-15742011000300006.

LOPES, Maria Marta da Silva; SANTOS, Luiz Alberto dos. Evasão escolar no ensino médio. Enciclopédia Biosfera, Goiânia, v. 11, n. 22, p. 3767-3775, dez. 2015. http://dx.doi.org/10.18677/Enciclopedia_Biosfera_2015_269.

LÜSCHER, Ana Zuleima; DORE, Rosemary. Política educacional no Brasil: educação técnica e abandono escolar. Revista Brasileira de Pós-Graduação, Brasília, v. 8, n. 1, p. 147-176, dez. 2011. https://doi.org/10.21713/2358-2332.2011.v8.244.

MENDES, Marcelo Simões. Da inclusão à evasão escolar: o papel da motivação no ensino médio. Estudos de Psicologia, Campinas, v. 30, n. 2, p. 261-265, jun. 2013. http://dx.doi.org/10.1590/S0103-166X2013000200012.

MILLEN NETO, Alvaro Rego et al. Evasão escolar e desinteresse dos alunos nas aulas de Educação Física. Pensar a Prática, Goiânia, v. 13, n. 2, p. 1-15, maio/ago. 2010. https://doi.org/10.5216/rpp.v13i2.7559. 
QUEIROZ, Maria Ireide Andrade de. Plano de desenvolvimento da escola (PDE) e sua gestão democrática na educação. Revista E-curriculum, São Paulo, v. 2, n. 2, p.1-17, jun. 2007.

REAL, Giselle Cristina Martins et al. Abandono, reprovação, reforço escolar: respostas de diretores ao questionário contextual da Prova Brasil. Revista Brasileira de Política e Administração da Educação, Brasília, v. 35, n. 1, p. 249-268, jan./abr. 2019. https://doi.org/10.21573/vol1n12019.86902.

SÃO PAULO. Secretaria da Educação. Índices educacionais auxiliam ações da Educação na busca constante pela melhoria da qualidade de ensino. São Paulo: SEDUC, 2017. Disponível em: http://www.educacao.sp.gov.br/indices-educacionais. Acesso em: 29 set. 2017.

SILVA, Fernanda Scaciota Simões da. O fluxo escolar (ou) o percurso escolar (ou) a taxa de escolarização: entendendo seus conceitos para o Brasil e para a França. In: CONGRESSO NACIONAL DE EDUCAÇÃO - EDUCERE, 13., 2017, Curitiba. Anais eletrônicos [...]. Curitiba: PUCPR, 2017. Disponível em: https://educere.bruc.com.br/arquivo/pdf2017/26865_13382.pdf. Acesso em: 17 nov. 2019.

SOUSA, Antonia de Abreu et al. Evasão escolar no ensino médio: velhos ou novos dilemas?. Revista Vértices, São Paulo, v. 13, n. 1, p. 25-36, 2011. https://doi.org/10.5935/1809$\underline{2667.20110002 .}$.

TROMBINI, Janaine; OLEGRÁRIO, Fabiane; LAROQUE, Luís Fernando da Silva. A evasão no ensino médio e as estratégias educacionais. Revista Intersaberes, Curitiba, v. 12, n. 25, p. 144-151, jan./abr. 2017.

\section{Checagem Antiplágio}

Crossref

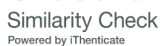

Distribuído sobre

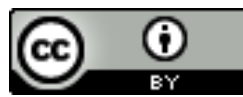

